\title{
DESIGN AND ANALYSIS OF A TOOL FOR PLANNING AND SIMULATING DYNAMIC VERTICAL TRANSPORT Single Page Description
}

\section{Original contribution of the work and its significance}

Nowadays most of the main companies in the vertical transport industry are researching on tools capable of providing support for the design process of elevator systems. Numerous decisions have to be taken in order to obtain an accurate, comfortable and high quality service. Some examples of these decisions are: the controller algorithm, the number of cars being installed, their technical characteristics, the kinematics of the elevator group, and some other design parameters.

The scarce existence of papers in this field is due to several aspects. Firstly, most of the works are led by private companies that are reluctant to give their technical advances to the public domain. Secondly, it is also due to the complexity of the vertical transport phenomenon. As it is, very few papers have been published on relevant scientific journals.

\section{Most closely related works and differences}

Not many papers can be referred in the scope of vertical transport simulation. The main references that we have found come from the Systems Analysis Laboratory of the Helsinki University of Technology, which usually collaborates with the KONE Corporation. These are works generally led by Dr. M-L. Siikonen. Examples are:

- Siikonen, M-L., Susi, T. and Hakonen, H. 2001. Passenger traffic flow simulation in tall buildings. Elevator World Magazine, July issue.

- Siikonen, M-L. 1993. Elevator traffic simulation, Simulation 61-4: 257-267.

- Siikonen, M-L. 1997. Planning and Control Models for Elevators in High-Rise Buildings. Helsinki University of Technology, Systems Analysis Laboratory, Research Reports A68.

In the late years, the simulators developed by KONE are including considerations on the building evacuation phenomenon (including the people flow across the building), since they consider the main aspects of elevator simulation covered by their previous ALTS.

Also, researchers from the Konrad-Zuse-Zentrum für Informationstechnik of Berlin have dealt with the elevator simulation problem but from an academic perspective.

One of our previous researches (Cortés, P., J. Larrañeta and L. Onieva. 2004. Genetic Algorithm for Controllers in Elevator Groups: Analysis and simulation during lunchpeak traffic. Applied Soft Computing 4: 159-174.) dealt with the elevator simulation problem. However, the simulation tool was developed using the Arena ${ }^{\odot}$ simulation software. It is software specially appropriate for manufacturing and logistic process but can be suitably modified in order to simulate vertical transport. Nevertheless the quality of the results is not comparable to the results reached by a specific vertical transport simulator.

Finally we have to mention the Elevate software, a commercial tool that is described by Dr. G. Barney in his volume Elevator traffic handbook. Theory and practice, one of the most complete books on the vertical transport field.

As can be viewed from table 1 of the paper, our tool provides a new perspective to approach the problem. It is a new point of analysis (with a wide coverage in the output reports, a high quality of simulation animation and with a quicker simulation engine capable of calculating the optimization algorithm output in the order of microseconds) improving several aspects of previous tools.

\section{Applicability of the results}

The results allow researchers in the field to have access to a detailed description of an existing application being used for a private company as decision support system for the design of elevator systems. The explanation is wide and covers the entire set of capabilities of the tool. It provides a clear idea of the state of the art of the vertical transport planning and simulation systems. 


\section{DESIGN AND ANALYSIS OF A TOOL FOR PLANNING AND \\ SIMULATING DYNAMIC VERTICAL TRANSPORT}

\section{Cover Page}

\section{Authors.}

Pablo Cortés. Grupo Ingeniería de Organización. Escuela Superior de Ingenieros. Universidad de Sevilla. c/ Camino de los Descubrimientos s/n 41013 Sevilla, Spain. pca@esi.us.es

Jesús Muñuzuri. Grupo Ingeniería de Organización. Escuela Superior de Ingenieros. Universidad de Sevilla. c/ Camino de los Descubrimientos s/n 41013 Sevilla, Spain. munuzuri@esi.us.es

Luis Onieva. Grupo Ingeniería de Organización. Escuela Superior de Ingenieros. Universidad de Sevilla. c/ Camino de los Descubrimientos s/n 41013 Sevilla, Spain. onieva@esi.us.es

Keywords.- vertical transport, simulation, elevator. 


\title{
DESIGN AND ANALYSIS OF A TOOL FOR PLANNING AND SIMULATING DYNAMIC VERTICAL TRANSPORT
}

\author{
Pablo Cortés, Jesús Muñuzuri, Luis Onieva
}

\begin{abstract}
Nowadays most of the main companies in the vertical transport industry are researching on tools capable of providing support for the design process of elevator systems. Numerous decisions have to be taken in order to obtain an accurate, comfortable and high quality service. Effectively, the optimization algorithm is a key factor in the design process, but also the number of cars being installed, their technical characteristics, the kinematics of the elevator group, and some other design parameters, which cause the selection task of the elevator system to be a complex one. In this context the design of decision support tools are becoming a real necessity that most important companies are including as part of their strategic plans. In this paper we present a user friendly planning and simulating tool for dynamic vertical traffic. The tool is conceptualized for giving support in the planning and design stage of the elevator system, in order to collaborate in the selection of the type of elevator (number, type of dynamic, capacity, etc.) and the optimization algorithm.
\end{abstract}

Keywords.- vertical transport, elevator, simulation. 


\section{DESIGN AND ANALYSIS OF A TOOL FOR PLANNING AND SIMULATING DYNAMIC VERTICAL TRANSPORT}

\section{Introduction}

Traditionally, the elevator controller implemented dispatch rules that made use of IFELSE logical commands sets. These dispatch strategies still work reasonably well for small buildings. However, the installation of synchronized elevator groups in professional use buildings (offices, hospitals or hotels) and in medium-size or higher buildings is today a usual practice. In fact, the existence of high buildings makes the management of the traffic extremely difficult, as well as the prediction of the effects of the elevator group control and traffic performance.

It has been said that only for morning peak (uppeak) situations where passengers arrive at the entrance floor and travel to the upper floors can the elevator traffic be calculated analytically [1]. For other traffic situations, such as interfloor or lunch-peak traffic the type of controller strongly affects the passengers' quality of service. It is even more unpredictable when non-deterministic methods are used in order to try to improve the quality of service.

Along this line, numerous algorithms are recently being designed and patented in order to improve the passengers' service quality in elevator systems. Most of them include Artificial Intelligence elements. Among them we can find algorithms based on learning as the controller Neuros-I [2] of Fujitec which is a neural network where the group elevator state and the lifts state are inputs for the neural network. The network has a previous learning and subsequent adaptive auto-tune online learning. Also, within the learning framework, Reinforcement Learning algorithms [3] have shown an accurate behaviour. They consist of a semi-Markovian process and use an agent team where each agent controls one lift. Under these conditions two architectures are used: a parallel architecture where the agents share the network $\left(\mathrm{RL}_{\mathrm{p}}\right.$, Parallel Reinforcement Learning) and a decentralised architecture where each agent has its own network $\left(\mathrm{RL}_{\mathrm{d}}\right.$, Decentralized Reinforcement Learning).

Fuzzy Logic has proved to be a valuable alternative when evaluating a large amount of criteria in a flexible manner. The fuzzy elevator group control system [4] and the Fuzzy Elevator Group Controller with Linear Context Adaptation [5] are some examples where diverse criteria are used, like the $\mathrm{HCWT}_{\mathrm{i}}$ (Hall Call Waiting Time for the i-lift), the maxHCWT $\mathrm{T}_{\mathrm{i}}$ (maximum Hall Call Waiting Time), the $\mathrm{CV}_{\mathrm{i}}$ (capacity of coverability for next calls for the i-lift), and the minimum distance between new calls and the last calls allocated $\mathrm{GD}_{\mathrm{i}}$ (Gathering Degree). Also along this line, genetic algorithms [6 and 7] have been used with success to adjust the control settings (a set of criteria) in order to give robustness to the elevator group control system, within a set of great variety of control parameters. These works allow adjusting the control settings according to individual floor utilization situations making use of a combination of car and floor attributes.

Evolutionary systems have also revealed successful capabilities in order to maximize the efficiency of the elevator system call allocation. Genetic algorithms [8] and [9] have been designed within a discrete event simulation trying to predict the optimal decisions 
for the car dispatch. Both are short papers with only a brief explanation of the methods used and with an additional difficulty when trying to identify the criterion used for assessing the quality of the solutions (by means of a performance index). However, the authors state the validation and success of the implementation by the representation of diverse figures and graphics. Also, a recent paper [10] describes a genetic algorithm to maximize the call allocation efficiency and to reduce the overall system waiting time (the authors name it GAHCA). It is a genetic algorithm based on a hall call allocation strategy to identify the chromosomes of the population individuals. In the paper, GAHCA was compared with conventional duplex controllers of the industry in a discrete event simulation scenario.

In fact, the design of such complex control and optimization algorithms in dynamic systems subject to the influence of non-controllable variables, typical in vertical traffic systems, need decision support tools helping the designer of elevator systems. According to these aspects, simulation becomes a practical tool to demonstrate the validation and accuracy of the methods and techniques as a previous step to the physical and real implementation. Not many papers can be found in this field. The most complete research on the field is due to M-L. Siikonen (see among others [1], [11] or [12]), a significant specialist in it and who is the author of several relevant papers. [13] is another technical paper from the Konrad-Zuse-Zentrum für Informationstechnik of Berlin dealing with the elevator simulation problem. Finally, in the previously referred paper [10] the well known Arena $\left.{ }^{(}\right)$simulation software is used to simulate the effects of the genetic algorithm proposed.

But not only the controller algorithm is a key factor in the design process, also the number of cars being installed, their technical characteristics, the kinematics of the elevator group, and some other design parameters cause the selection task of the elevator system to be a complex one. Along this line, the design of decision support tools is being considered an actual necessity that most of the important companies are including as part of their strategic plans.

In this paper we present a tool (named SimMP) capable of planning and simulating dynamic vertical traffic. SimMP is conceptualized for giving support in the planning and design stage of the elevator system, in order to collaborate in the selection of the type of elevator system (number, type of dynamic, capacity, etc.) and the optimization algorithm. It is a user-friendly planning and simulating tool that allows navigating through graphical interfaces and appreciating a visual simulation of the system, and at the same time obtaining complete and detailed results for the parameters and set of characteristics selected. SimMP is a tool that has been developed for the MAC PUAR S.A. Company (MP) by the Ingeniería de Organización research group of the University of Seville.

The rest of the paper follows with the second section dealing with the architecture and functional requirements. It is a detailed section that explains the main facilities of the tool. The third section brings a comparison between the main simulators known in the vertical transport industry. The fourth section is dedicated to the analysis of a concrete case study, and finally we highlight the main conclusions in the final section. 


\section{Architecture and Functional Requirements}

SimMP has been designed using Borland C++ Builder 6 and must be run on Windows NT or Windows XP platforms. It requires minimum hardware specifications, such as equipment Pentium $600 \mathrm{MHz}$ or equivalent with $64 \mathrm{MB}$ RAM. With these conditions a satisfactory performance is expected.

Figure 1 depicts the main aspects of its architecture.

\section{FIGURE 1}

The tool has a database set with adaptable configurations for several types of buildings (with diverse typologies as for example housings, professional uses, etc.), as well as different elevator technologies and functional specifications. A database for feasible traffic is also loaded. However, the user can modify or create new data for all these aspects.

The system includes a set of optimization algorithms. Nevertheless, the user can design any kind of optimization algorithm according to the specifications of the dll input file that allows the correct performance of the simulation engine.

SimMP output includes graphical and text reports that allow the user to select among diverse tests for alternative configurations of the elevator group characteristics and/or the elevator controller.

The tool includes an advanced configuration interface, as well as a quick start option with most of the values pre-selected. The advanced aspects are detailed and discussed in the next subsections.

\subsection{Building configuration}

The building data can be accessed by means of the Configuration option in the menu bar and selecting Building, or directly clicking on the icon $\mathrm{O}$ from the tool bar. The building configuration screen is depicted in Figure 2.

\section{FIGURE 2}

The building can be configured manually or by selecting an available configuration. In order to do so, a display changes manual to the list of available configurations.

In case of selecting a user configuration the system allows to state:

- Number of floors

- Number of entrance doors, i.e., the option of considering different boarding gates for one specific car. For example, this is the case of several buildings (or different parts of the same building) being served by the same elevator group.

- Typology of building. SimMP considers different types of buildings: housing, office, housing with offices, hotel, hospital, shopping centres, etc.

After that for each floor their characteristics can be selected: 
- Name of the floor. It can be the basement, the ground floor, the attic or any other floor.

- The position of the floor (for example, the height in metres with respect to the ground floor)

- The separation of the floor with respect to the other adjacent floors. The tool warns the user in case of separations lower than 2 metres with yellow colour and red colour for separations lower than 0 metres.

- Data relative to the entrances (note that more than one can be acceptable for each car).

o Typology (housing, office, hotel, etc.) of the entrance.

o Potential population in the entrance access.

Another option for a quick generation is using the button Create Building. In this case a menu is displayed and the user is only required to select the number of floors, number of basements, generic separation between floors, typology of the building and average population by floor. Figure 3 shows the quick building generation button.

\section{FIGURE 3}

Finally, every configuration can be saved with a file extension .edi, and every saved configuration can be edited.

\subsection{Traffic generation}

The traffic data is accessed by selecting Configuration in the menu bar and then the option Traffic, or directly by clicking on the icon fin the tool bar. The traffic configuration screen is shown in Figure 4.

\section{FIGURE 4}

The screen is divided in two different sections. The first one corresponds to the passenger characterization and the second one is concerned with the traffic pattern definition.

In the passengers' section, the average weight, the door crossing time for entering and leaving the cars, the capacity factor that prevents passengers from loading the elevators up to their rated capacity and the stair factor for those passengers preferring the stairs to the elevators should be selected.

The traffic pattern configuration can be constructed in a simple mode or in an advanced one, as follows.

The simple mode defines only uppeak, downpeak or lunchpeak traffic rates. The uppeak pattern consists of a traffic main stream from the ground or basement floors to the rest of floors. The downpeak pattern consists of a main stream from the floors to the ground and basement. Finally, the lunchpeak pattern takes place at the lunch hours being a mix of the uppeak and downpeak situations. Figure 5 depicts the options for the lunchpeak case. In the figure, the uppeak and downpeak rates are selected and the percentage travelling to the basement or ground floor must be stated. 


\section{FIGURE 5}

Also, the configuration of the traffics can be selected using the peak pattern option. Unlike the constant arrival rate option, the peak pattern option allows the traffic characterization by means of a function constructed from the peak rate (maximum arrival rate in passenger/minute or percentage of the population per floor every five minutes), the basic rate (constant arrival rate for the simulation period) and the peak width (peak duration expressed in minutes). Figure 6 shows the screen for this option.

\section{FIGURE 6}

The advanced mode allows a more detailed description of the traffic. The user must select the arrival rate of passengers every five minutes per floor. After that, their destinations must be selected for each floor and entrance, as a probability percentage. It should be done for every 5-minute intervals of the simulation period, but a fast-fill option can be used: the option consists of completing the data for the first 5-minute interval and then extending the same pattern to the rest of intervals. Figure 7 depicts the screen options. The tool warns the user when the sum of the percentages is not $100 \%$ (with diverse colours).

\section{FIGURE 7}

In order to generate the traffic, we followed the CIBSE Guide D for Transportation systems in buildings [14] that states the commonly accepted rules to design building services from an engineering perspective. It states as generally accepted that a Poisson process reasonably approximates the arrival of passengers (individuals) at a lift landing station. This gives the result:

$$
p(n)_{i, j}=\frac{\left(\lambda_{i} \mathrm{INT}_{i, j}\right)^{n}}{n !} e^{-\lambda_{i} \mathrm{INT} d_{i, j}}
$$

Where $p(n)_{i, j}$ is the probability of $n$ passengers wanting to travel from floor $i$ to floor $j$ during the time interval INT, where INT is the system interval, when the arrival rate is equal to $\lambda_{i}$. Here it is important to note that the non-stationary Poisson traffic is created by the thinning of a Poisson stream that is generated with the maximum arrival rate found in the observation interval (see for instance [15]).

When calculating probabilities, in order to determine the probability of an event happening, it is sometimes easier to calculate the probability of the event not happening and subtracting this from unit. So, let:

$$
p_{i, j}=p(0)_{i, j}
$$

Which is the probability of no calls from the $i$ th to the $j$ th floor in the time interval INT.

From equation (1):

$$
p_{i, j}=e^{-\lambda_{i} \mathrm{INTd} d_{i, j}}
$$


Applying this result, formulae for probable number of stops, lowest and reversal floors are derived (see CIBSE Guide for details), as well as the calculus of the Round Trip Time.

The case of simple mode uses one unique maximum arrival rate $(\lambda)$ for the whole simulation period, and the advanced mode allows different maximum arrival rates $(\lambda)$, one for every 5-minute slice. These suppositions are common base for all vertical traffic simulators. In particular, we have followed in these aspects the same specifications of the Elevate ${ }^{\mathrm{TM}}$ software [16].

Finally, every configuration can be saved with a file extension .tra, and every saved configuration can be edited.

\subsection{Elevator group configuration}

The elevator group data is accessed by selecting Configuration in the menu bar and then the option Elevators, or directly by clicking on the icon $\square$ from the tool bar. The elevator group configuration screen is shown in Figure 8.

\section{FIGURE 8}

The control box located on the top-left side allows the selection of the number of elevators in the group for the simulation. The tool can also be used to select different options for the elevator group. Then the system simulates all the options providing the different results.

This screen also allows the selection of floors with access forbidden. The button Closed Board is located on the top-right side.

The rest of the screen states the main parameters of the elevator group. The tool allows editing an existing configuration, and it also allows selecting:

- Capacity of the elevator. Different capacities can be used in order to test the different options.

- Door times. The door pre-open and door open times for the instant of the elevator car being level at a floor to the instant when the doors are fully open; the door dwell 1 for the time that the doors wait until closing if the passenger detection beam across the door entrance is not broken; and the door dwell 2 for the time that the doors wait until closing after the broken passenger detection beams are cleared.

- Kinematics of the elevator group. The tool considers two different types: 2-speed and 3VF kinematics.

o 2-speed kinematics is characterized by the starting delay (the interval between the door closed and the start of the car), the nominal speed (maximum speed in steady state), the slow speed (reduced speed when approaching the destination floor) and the slow time (time interval with the elevator travelling at low speed). Figure 9 depicts the kinematics for this case.

\section{FIGURE 9}


o 3VF kinematics is characterized by the starting delay (the interval between the door closed and the start of the car), starting acceleration, nominal speed (maximum speed in steady state after accelerating), stopping deceleration, slow speed (speed after the deceleration stage) and the slow time (time interval with the elevator travelling at low speed). Figure 10 depicts the kinematics for this case.

\section{FIGURE 10}

Finally, every configuration can be saved with a file extension .asc, and every saved configuration can be edited.

\subsection{Optimization algorithm configuration}

The optimization algorithm configuration is accessed by selecting Configuration in the menu bar and then the option Algorithm, or directly by clicking on the icon $\sum_{\Omega}^{2}$ from the tool bar. The screen is shown in Figure 11.

\section{FIGURE 11}

The screen has a display that allows selecting the set of algorithms from the dynamic link library or selecting any other $d l l$ input file with the appropriate format.

Figure 11 shows the configuration parameters for one algorithm from the Microbasic ${ }^{\circledR}$ algorithms' family. The option includes the down collective, up collective or full collective options powered with uppeak or downpeak additional controls together with a longest waiting time control.

\subsection{Animation zone}

Once the data have been introduced in the simulation and planning tool, the animation starts by clicking on the play icon $\downarrow$ from the tool bar. Figure 12 shows an instance of the simulation screen. The screen allows monitoring the evolution of the building vertical transport life for the time period simulated.

\section{FIGURE 12}

The top-left side of the window gives information related to the timer, RTT (Round Trip Time), and AWT (Average Waiting Time for passengers whose calls have already been answered). The top-right side gives information related to the physical location of the cars, their speeds and load.

In the middle of the screen a friendly image of the simulation scenario is displayed. The visual information includes the queues to the entrances of the floors, the number of passengers travelling in the cars, as well as the evolution of the cars through the building.

In the lower side, the simulation progress and basic configuration data being simulated are shown. 
The animation can be controlled by pausing the simulation, forwarding, rewinding, accelerating and decelerating. So the processing can be accelerated at maximum in the order of seconds. Also zoom and adjusting buttons are available.

\subsection{Output text and graphical report}

The report configuration is accessed by selecting Configuration in the menu bar and then the option Report, or directly by clicking on the icon from the tool bar. When configuring the report the user should indicates the specific reports to be generated, see Figure 13.

\section{FIGURE 13}

The options include:

- Global results:

o Waiting time. It is the average time for passengers whose calls have already been served.

o Trip (or journey) time. It is the time of passengers travelling inside the car.

o System (or total) time. It is the average time of passengers who have already completed their journey. It includes the waiting time plus the trip time.

- Elevator results:

o Position. It shows the position of the elevator during the simulation

o Load. It shows the load transported by the elevator during the simulation.

- Floor results:

o Queue size. It indicates the queue size for each floor entrance.

o Arrival rate. It indicates the arrival rate at the entrances of the floor.

The report screen includes possibilities for filtering the results according to a bounded longest waiting (or system) time, and sorting the results by average waiting time (AWT) or average system time (ATT). The report file can be saved as a $p d f$ file.

An example of the report output is described in section 4, which is dedicated to a case study.

\section{A Comparison between SimMP and other Vertical Traffic Simulators}

In this section we compare SimMP with three other vertical traffic simulators. One of them is freeware (PC-LSD, Personal Computer - Lift System Design and developed at the University of Manchester Institute of Science and Technology), and another is a commercial software (Elevate $^{\mathrm{TM}}$, commercial software from Peters Research Ltd.). An exhaustive comparison between Elevate ${ }^{\mathrm{TM}}$ and PC-LSD can be found in [17], and for a detailed description about Elevate ${ }^{\mathrm{TM}}$ see [16]. The Elevate software is mainly based on Dr. Peters' developments and it is commercialized by Peters Research Ltd. The main characteristics of Elevate were introduced in [18].

The rest of the simulators are property of private companies. Along this line we have included ALTS (Advanced Lift Traffic Simulator) in the analysis, a simulator that was created by KONE Corporation in cooperation with the Systems Analysis Laboratory of 
the Helsinki University of Technology. From 2001 to 2003, KONE developed BTS (Building Traffic Simulator) a new tool that improved ALTS and that included building evacuation analysis. We include the comparison for ALTS/BTS with respect to the characteristics that have been published related to these simulators, since the tool is property of a private company and it is not open to public domain. Finally we include our SimMP.

Table 1 summarises the main characteristics of the different simulators analysed.

\section{TABLE 1}

Table 1 compares the characteristics of the three simulators that we have been able to find explained in depth in the scientific literature. However, there are other simulators that are property of private companies. OTISPLAN ${ }^{\circledR}$ from Otis [19] is an on-line elevator planning tool used by Otis sales associates that comprises three major applications: (1) single group performance tool for calculating up-peak round trip time, interval, and handling capacity, (2) multiple group optimization for determining good banking arrangements for high buildings requiring two or more groups, and (3) dispatcher performance simulation for evaluating performance of individual Otis controllers against two-way and down peak traffic. However, most of the parameters that are marked in Table 1 are not specified, so we have not been able to include it in the comparison table. Also, Schindler Lifts Ltd. has been involved in simulators for elevator systems. Project HILS (Hardware-in -the-loop Simulator for Elevator Systems) is an example of the Company's activity in this field. However, not much information has come out from this type of initiatives in scientific publications.

\section{Case Study}

In order to experiment some of the facilities of SimMP, we consider a case study in this section. Let us consider the case of a building with 7 levels (including the ground floor, a basement and 5 floors, the first one of them dedicated to offices and the rest for residential use). The population per floor is 10 people and 40 people in the office floor.

The traffic considered is lunchpeak for a time interval between 13.30 and 15.30 hours (a typical Spanish lunch schedule). The arrival rate for the uppeak stage is equal to 20 passengers every 5 minutes and the arrival rate for the downpeak phenomenon is equal to 10 passengers every 5 minutes. The passengers' transit time is considered equal to 1.2 seconds, and a capacity factor of $80 \%$ has been considered. We do not consider stair factor for this case study. This arrival data were lightly varied in order to appreciate modifications in the expected results. After examining the results, we could note that the elevator group systems evaluated were robust enough with respect to changes in the arrival data.

We want to analyse the effects of installing 2 or 3 cars for the elevator group. We consider $300 \mathrm{~kg}$ capacity for the cars. The kinematics selected is 3VF with nominal starting delay equal to 0.5 seconds, speed equal to $1 \mathrm{~m} / \mathrm{s}$, low speed $0.10 \mathrm{~m} / \mathrm{s}$, acceleration and deceleration equal to $2 \mathrm{~m} / \mathrm{s}^{2}$ and slow time equal to 1 second. The door open time is equal to 1 second; the door closing time equal to 2 seconds; the door dwell 1 is 3.5 seconds and the door dwell 2 is 2 seconds. 
Finally, the optimization algorithm is the lowest estimated arrival time (ETA) algorithm. Figure 14 depicts the input data in the main screens.

\section{FIGURE 14}

The report is divided into a text report and a graphic report. The text report starts with the summary of the simulation results. For the more extensive case, it includes the average waiting time (AWT), the longest waiting time (LWT), the average system, or total, time (ATT) and the LTT (the longest system time). After that the number of starts (which is used as an energy consumption indicator), the kinematics parameters, and the number and capacity of the elevator group are shown. The summary is displayed for the total number of different configurations analysed. It must be considered that several configurations can be analysed in a same simulation test in order to allow the planning of the vertical transport system. The text report includes the data of the building, the traffic configuration specifications, as well as the optimization algorithm tested. The summary of the simulation results is shown in Table 2.

\section{TABLE 2}

In order to eliminate the random effect, we carried out 200 replications, and we observe a maximum deviation in the results provided by the application lower than 5\%. Even more, we were able to check the results provided by the tool with respect to the results from the real tests in the physical test tower of the company appreciating a close accuracy between real-life tests and the simulation tool.

Attending to the tool results, we can appreciate that configuration 2 offers better performance than configuration 1 . However, the results from configuration 1 are also good and allow reducing the investment in another lift (it is a configuration with 2 lifts). So for this case we will select configuration 1 with an average waiting time equal to 28.55 seconds, which is a good waiting time, and a longest waiting time not higher than 272.09 seconds (4 minutes and a half).

It is important to note that lunchpeak traffic is the most critical situation in vertical traffic, because it includes the uppeak and downpeak traffic effects. However, the results should be checked with other traffic situations (as pure uppeak or downpeak traffic, as well as interfloor traffic).

Once we have stated these restrictions, in order to follow with the case study, we select configuration No. 1 for the case. And therefore we will show the results for this configuration in the next graphic report. Typically, the graphic report consists of three different parts: a global results part, an elevator results part, and a floor results part.

Starting with the global results part, the report indicates the detailed configuration being analysed and it shows the average Round Trip Time (RTT), as well as the AWT, LWT, AJT (average journey time), LJT (longest trip time), ATT and LTT. It also indicates the numerical values of percentile passengers $10 \%, 50 \%$ and $90 \%$ with respect to all these times. Graphical information is shown for all these results. Figure 15 depicts the global result report.

\section{FIGURE 15}


Figure 15 shows that less than $5 \%$ of the passengers have to wait for more than one minute, which represents good waiting time results. Moreover, the results prove that the algorithm was processing in the order of microseconds as average time.

Continuing with the part of the elevator report, the average RTT for each specific elevator is shown, as well as the total distance covered by the elevator (including the total distance, and the distance for up and down traffics), and the number of trips (including the total traffic, as well as the up and down traffics).

In the second part of the report the transported passengers, the average load and the average occupation is reported. Graphical information is depicted for all the data and Figure 16 shows the results for the case. RTT for lift 1 was equal to 50.28 seconds and for lift 250.47 seconds, that is, less than one minute for the two cars. The average load was $90.91 \mathrm{Kg}$ for lift 1 and $89.66 \mathrm{Kg}$ for lift 2, i.e. approximately 1.2 passengers per journey. 325 passengers were transported by car No. 1, and the car was started 385 times. With respect to car No. 2, 320 passengers were transported, and the car needed 394 starts.

\section{FIGURE 16}

Finally, the floor result report indicates the values related to the queue sizes for each selected floor, as well as the arrival rates and the waiting times in floors for each car. Also, the number of calls per floor is calculated. To give an example, in Figure 17 we show the results for the ground floor. That is the most complex floor due to its intensive use during the uppeak effect. But the data for the rest of floors were also calculated and information reports are available, in the same line of the ground floor case. The graphic shows the results of queue sizes in the ground floor (longest queue equal to 5 and average queue less than one passenger), average arrival rate to the ground floor (8.63 people every 5 minutes) and AWT in the ground floor (AWT $=14.78$ seconds and LWT $=67.08$ seconds).

\section{FIGURE 17}

\section{Conclusion and Further Research}

Today most of the companies developing elevator group systems are focusing their research efforts on tools capable of providing support for elevator system design processes. SimMP takes part in this context. The objective of SimMP is not only to provide a simulation tool but a tool capable of helping designers in the vertical transport system design process. The tool allows selecting the number of cars to be installed, the kinematics group, the technical characteristics of the elevator group and of each specific car, as well as the optimization algorithm among several other options accordingly with the building profile.

This user-friendly tool covers most of the needs of the vertical transport system designers, when it is compared with respect to other tools. In many cases, it even provides a wider scope than the existing ones. 
As further research we continue working together with MP on the control and optimization scope, trying to integrate components of advanced Artificial Intelligence into the controllers of the system. The objective is to design an intelligent controller capable of providing improved solutions for extremely complex cases of vertical transport in buildings. However, the implementation of such type of algorithms in real controllers has to be done carefully in order to maintain the response time of the algorithm within bounds. With the objective of testing the suitability and feasibility of the algorithm controller, SimMP will play a decisive role.

\section{Acknowledgements}

The authors would like to thank MAC PUAR, S.A. for the support of this research since 2000. Also, the authors acknowledge the financial support given by the Ministerio de Ciencia y Tecnología, in its Industrial Production and Design programme (project ref. DPI2002-01264), Spain.

\section{References}

[1] Siikonen, M-L., Susi, T. and Hakonen, H. 2001. Passenger traffic flow simulation in tall buildings. Elevator World Magazine, July issue.

[2] Sasaki, K., S. Markon and M. Makagawa. 1996. Elevator Group Supervisory Control System Using Neural Networks, Elevator World Magazine, January issue.

[3] Crites, R.H. and A.G. Barto. 1996. Improving elevator Performance Using Reinforcement Learning, Advances in Neural Information Processing Systems 8. MIT Press.

[4] Kim, C., K.A. Seong and H. Lee-kwang. 1998. Design and implementation of a fuzzy elevator group control system. In Proceedings of the IEEE Transactions on systems, man and Cybernetics 28-3: 277-287.

[5] Gudwin, R., F. Gomide and M.A. Netto. 1998. A Fuzzy Elevator Group Controller with Linear Context Adaptation. In Proceedings of FUZZ-IEEE98, WCCI'98 IEEE World Congress on Computational Intelligence, Anchorage, Alaska, USA 481-486.

[6] Fujino, A., T. Tobita, K. Segawa, K. Yoneda and A. Togawa. 1997. An Elevator Group Control System with Floor-Attribute Control Meted and System Optimization using Genetic Algorithms. IEEE Transactions on Industrial Electronics 44-4: 546-552.

[7] Tobita, T. A. Fujino, K. Segawa, K. Yoneda and Y. Ichikawa. 1998. A Parameter Tuning Meted for an Elevator Group Control System using a Genetic Algorithm. Electrical Engineering in Japan. 124-1: 55-64.

[8] Gudwin, R. and F. Gomide. 1994. Genetic Algorithms and Discrete Event Systems: An Application. In Proceedings of The First IEEE Conference on Evolutionary Computation. IEEE World Congress on Computational Intelligence II: $742-745$.

[9] Alander, J.T., J. Ylinen and T. Tyni. 1995. Elevator Group Control Using Distributed Genetic Algorithm. In Proceedings of the International Conference. Springer-Verlag, Vienna, Austria 400-403.

[10] Cortés, P., J. Larrañeta and L. Onieva. 2004. Genetic Algorithm for Controllers in Elevator Groups: Analysis and simulation during lunchpeak traffic. Applied Soft Computing 4: 159-174.

[11] Siikonen, M-L. 1993. Elevator traffic simulation, Simulation 61-4: 257-267. 
[12] Siikonen, M-L. 1997. Planning and Control Models for Elevators in High-Rise Buildings. Helsinki University of Technology, Systems Analysis Laboratory, Research Reports A68.

[13] Grötschel, M. et al. 1999. Simulation studies for the online dial-a-ride problem, Konrad-Zuse-Zentrum für Informationstechnik Berlin, Preprint SC99-09.

[14] The Chartered Institution of Building Services Engineers London. 2000. CIBSE Guide D. Transportation systems in buildings. CIBSE Publications Department, Norfolk.

[15] Law, A.M. and Kelton, W.D. 1991. Simulation modelling and analysis. McGrawHill, Inc., $2^{\text {nd }}$ edition.

[16] Caporale, R.S. 2000. Elevate traffic analysis software (eliminating the guesswork), Elevator World, June 2000: 118-121.

[17] Barney, G. 2003. Elevator traffic handbook. Theory and practice. Spon Press, Taylor and Francis Group, London and New York.

[18] Peters, R.D. 1998. Simulation for control system design and traffic analysis, Elevator Technology 9, Proceedings of ELEVCON'98 (The International Association of Elevator Engineers).

[19] Powell, B.A. 2002. Elevator planning and analysis on the Web, Elevator World, June 2002: 73-77. 
TABLES

Table 1. A comparison of simulators

\begin{tabular}{|c|c|c|c|c|}
\hline Item & PC-LSD & Elevate $^{\mathrm{TM}}$ & ALTS/BTS & SimMP \\
\hline \multicolumn{5}{|c|}{ System characteristics } \\
\hline Operating System & DOS & Windows & Windows & Windows \\
\hline $\begin{array}{l}\text { Language } \\
\text { programming }\end{array}$ & FORTRAN IV & Visual C++ & Standard C++ & $\begin{array}{l}\text { Borland C++ } \\
\text { Builder } 6\end{array}$ \\
\hline $\begin{array}{l}\text { Special PC } \\
\text { requirements }\end{array}$ & No & No & No & No \\
\hline $\begin{array}{l}\text { Quick starting } \\
\text { option }\end{array}$ & No & No & $\mathrm{n} / \mathrm{a}$ & Yes \\
\hline \multicolumn{5}{|c|}{ Building configuration } \\
\hline Number of floors & 25 & 100 & No-limit & $\begin{array}{l}30 \text { (including } \\
\text { extensive } \\
\text { facilities) }\end{array}$ \\
\hline Interfloor distance & No & Yes & Yes & Yes \\
\hline $\begin{array}{l}\text { Floors with } \\
\text { special conditions }\end{array}$ & No & Yes & Yes & Yes \\
\hline $\begin{array}{l}\text { Several entrance } \\
\text { to the cars }\end{array}$ & No & No & $\mathrm{n} / \mathrm{a}$ & Yes \\
\hline \multicolumn{5}{|c|}{ Traffic configuration } \\
\hline $\begin{array}{l}\text { Special traffic } \\
\text { flows (uppeak, } \\
\text { downpeak, etc.) }\end{array}$ & Yes & Yes & Yes & $\begin{array}{l}\text { Yes (including } \\
\text { lunchpeak) }\end{array}$ \\
\hline $\begin{array}{l}\text { Simple definition } \\
\text { of destinations }\end{array}$ & Yes & Yes & Yes & Yes \\
\hline $\begin{array}{l}\text { Advanced } \\
\text { definition of } \\
\text { destinations } \\
\end{array}$ & No & Yes & Yes & Yes \\
\hline Floor populations & Yes & Yes & Yes & Yes \\
\hline $\begin{array}{l}\text { Passengers } \\
\text { transfer times }\end{array}$ & Yes & Yes & Yes & Yes \\
\hline $\begin{array}{l}\text { Stair/capacity } \\
\text { factors }\end{array}$ & No & Yes & Yes & Yes \\
\hline \multicolumn{5}{|c|}{ Elevator configuration } \\
\hline Number of lifts & 8 & 12 & No-limit & 12 \\
\hline $\begin{array}{l}\text { Floor entrance } \\
\text { forbidden option }\end{array}$ & No & No & $\mathrm{n} / \mathrm{a}$ & Yes \\
\hline $\begin{array}{l}\text { Lifts of different } \\
\text { capacities }\end{array}$ & No & Yes & $\mathrm{n} / \mathrm{a}$ & Yes \\
\hline $\begin{array}{l}\text { Several } \\
\text { kinematics }\end{array}$ & No & Yes & $\mathrm{n} / \mathrm{a}$ & Yes \\
\hline $\begin{array}{l}\text { Advanced door } \\
\text { openings }\end{array}$ & Yes & Yes & Yes & Yes \\
\hline \multicolumn{5}{|c|}{ Control and optimization algorithm configuration } \\
\hline $\begin{array}{l}\text { Traffic control } \\
\text { algorithms }\end{array}$ & $\begin{array}{l}\text { Collective } \\
\text { Nearest car } \\
\text { Dynamic } \\
\text { sectoring } \\
\text { Hall call } \\
\text { allocation } \\
\text { ETA (Lowest } \\
\text { Estimated Time of } \\
\text { Arrival) } \\
\text { Stochastic control }\end{array}$ & $\begin{array}{l}\text { Collective } \\
\text { Dynamic } \\
\text { sectoring } \\
\text { Hall call } \\
\text { allocation } \\
\text { ETA } \\
\text { Elevate } \\
\text { proprietary } \\
\text { algorithms }\end{array}$ & $\begin{array}{l}\text { KONE proprietary } \\
\text { algorithms } \\
\text { (among others } \\
\text { Enhanced Spacing } \\
\text { Principle, KONE } \\
\text { Genetic } \\
\text { Algorithms) }\end{array}$ & $\begin{array}{l}\text { MP proprietary } \\
\text { algorithms } \\
\text { (among others } \\
\text { Microbasic, } \\
\text { PDCU, MP } \\
\text { Genetic } \\
\text { Algorithms) and } \\
\text { any other } \\
\text { compatible with } \\
\text { dlls }\end{array}$ \\
\hline \multicolumn{5}{|l|}{ Simulation } \\
\hline Visual simulation & 2D design / Basic & 2D design / Basic & Advanced 3D & Advanced 2D \\
\hline
\end{tabular}




\begin{tabular}{|c|c|c|c|c|}
\hline & movements & $\begin{array}{l}\text { movements (cars- } \\
\text { directions) }\end{array}$ & $\begin{array}{l}\text { design plus 2D } \\
\text { basic movements } \\
\text { (cars- directions) }\end{array}$ & $\begin{array}{l}\text { design / } \\
\text { passengers-cars- } \\
\text { directions-queues- } \\
\text { doors }\end{array}$ \\
\hline $\begin{array}{l}\text { Simulation with } \\
\text { several } \\
\text { configurations in } \\
\text { series }\end{array}$ & No & No & Yes & Yes \\
\hline Select time slices & No & Yes & Yes & Yes \\
\hline \multicolumn{5}{|l|}{ Output reports } \\
\hline $\begin{array}{l}\text { Summary of input } \\
\text { data }\end{array}$ & Yes & No & Yes & Yes \\
\hline Printed output & Yes & Yes & Yes & Yes \\
\hline $\begin{array}{l}\text { Exportable } \\
\text { options }\end{array}$ & $\begin{array}{l}\text { Yes (word } \\
\text { processor) }\end{array}$ & $\begin{array}{l}\text { Yes (Microsoft } \\
\text { Excel }^{\circledR} \text { ) }\end{array}$ & $\begin{array}{l}\text { Yes (Microsoft } \\
\text { Access }^{\circledR} \text {, } \\
\text { Microsoft Word }^{\circledR} \text { ) }\end{array}$ & $\begin{array}{l}\text { Yes (portable } \\
\text { document format, } \\
\text { Adobe }^{\circledR} \text { ) }\end{array}$ \\
\hline Graphical report & $\begin{array}{l}\text { Waiting time } \\
\text { graphs. } \\
\text { Trip time graphs. } \\
\text { Car spatial graphs. } \\
\text { Car load graphs. } \\
\text { Percentile graphs. } \\
\text { Number of calls } \\
\text { graphs. }\end{array}$ & $\begin{array}{l}\text { Waiting time } \\
\text { graphs. } \\
\text { Trip time graphs. } \\
\text { Car spatial graphs. } \\
\text { Percentile graphs. }\end{array}$ & $\begin{array}{l}\text { Waiting time } \\
\text { graphs. } \\
\text { Trip time graphs. } \\
\text { Car load graphs. } \\
\text { They claim to be a } \\
\text { several graphical } \\
\text { options but we } \\
\text { have not } \\
\text { constancy of } \\
\text { which type. }\end{array}$ & $\begin{array}{l}\text { Waiting time } \\
\text { graphs. } \\
\text { Trip time graphs. } \\
\text { Car spatial graphs. } \\
\text { Car load graphs. } \\
\text { Car occupation } \\
\text { graphs. } \\
\text { Percentile graphs. } \\
\text { Queue graphs. } \\
\text { Waiting time in } \\
\text { floor entrances } \\
\text { graphs. } \\
\text { Number of calls / } \\
\text { arrival graphs. }\end{array}$ \\
\hline
\end{tabular}

Table 2. Summary of the simulation

Project description (Project1)

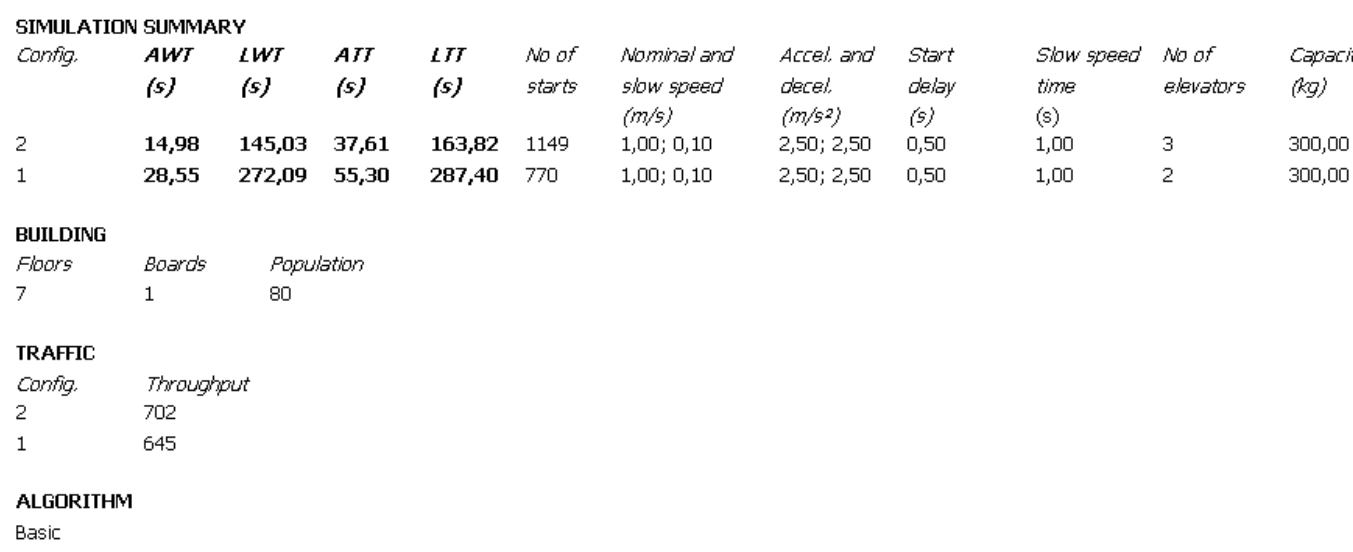




\section{FIGURES}

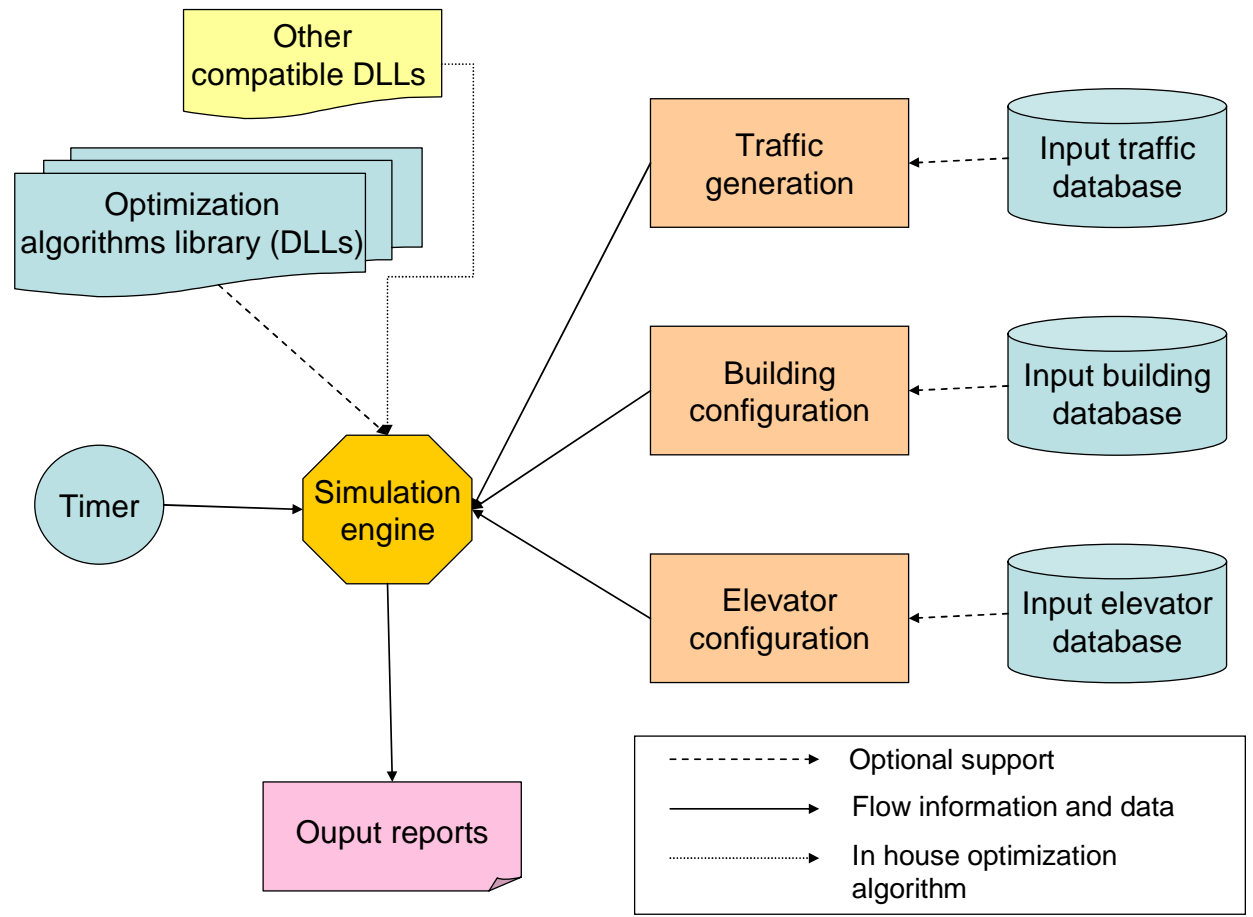

Figure 1. SimMP architecture 


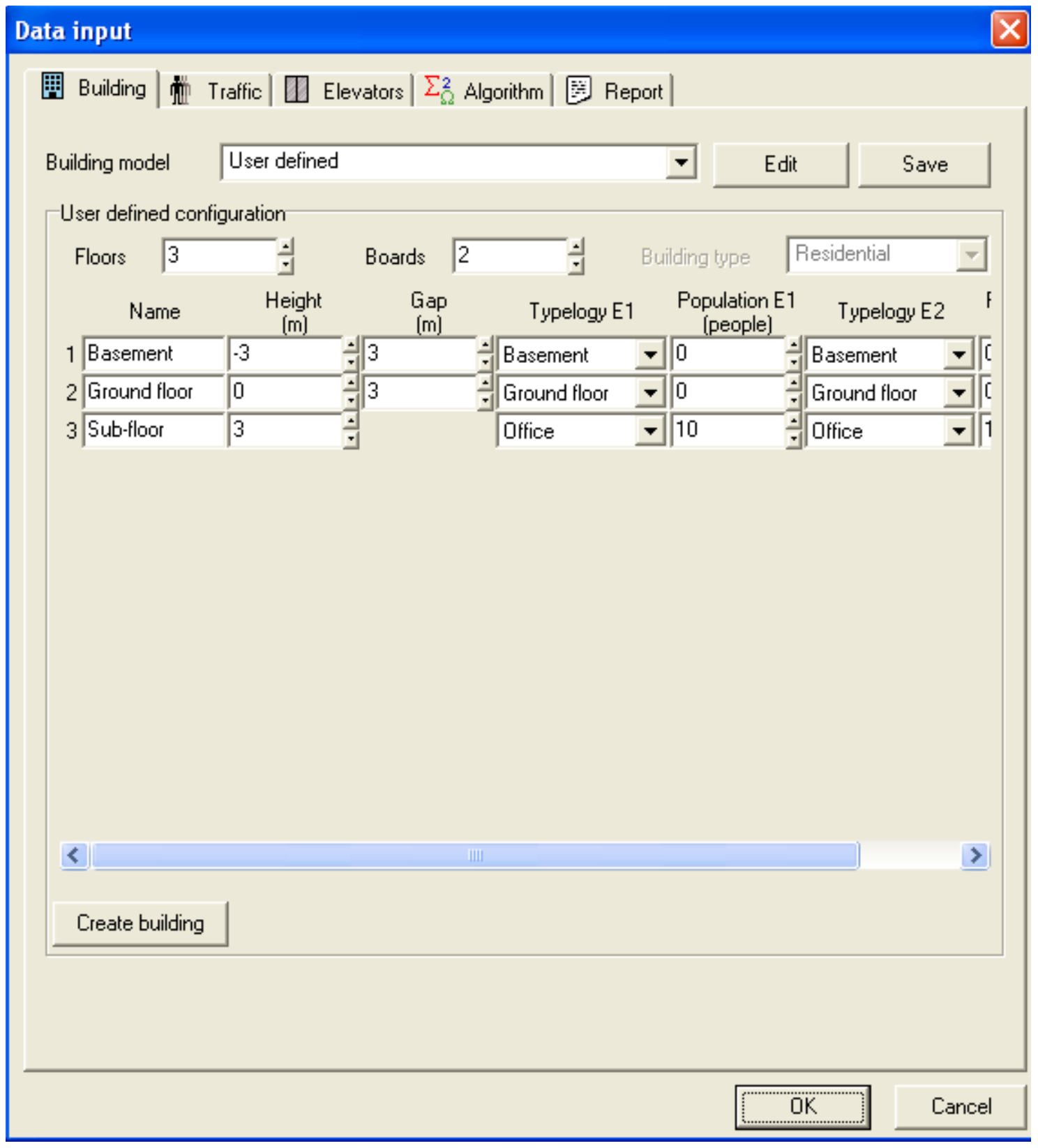

Figure 2. Building configuration screen

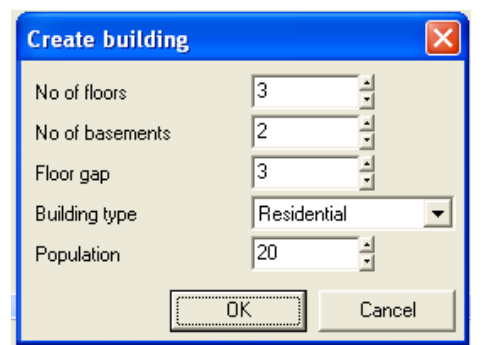

Figure 3. Quick building configuration 
Data input

囲 Building inj Traffic $\mid$ Elevators $\mid \sum_{\Omega}^{2}$ Algorithm| 圈 Report $\mid$

\begin{tabular}{|c|c|c|c|c|c|}
\hline \multicolumn{6}{|l|}{ Passengers } \\
\hline Weight & 75 & $\mathrm{~kg}$ & Capacity factor & 80 & $\div \%$ \\
\hline Entrance time & 1.2 & $\div s$ & Stairs factor & 0 & $\div \%$ \\
\hline Exit time & 1,2 & $\div s$ & VIP percent & 0 & \% \\
\hline
\end{tabular}

\begin{tabular}{ll|l|l|l|}
\cline { 2 - 3 } Traffic model & User defined & Save \\
\hline
\end{tabular}

User defined configuration

Traffic setup $\quad$ Simple (Uppeak, downpeak and interfloor rate by entrance)

-Traffic type

- Uppeak $\quad$ Г Group boards

$\checkmark$ Downpeak $\quad \Gamma$ Use peak pattern

C Lunchpeak

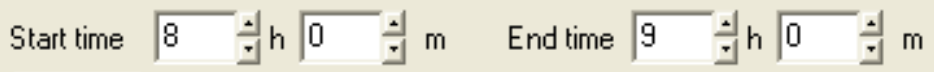
Board 1 | Board 2|

\begin{tabular}{|c|l|l|l|l|}
\hline & $\begin{array}{c}\text { Arrival rate } \\
\text { [people/5m) }\end{array}$ & $\begin{array}{c}\text { Arrival rate } \\
{[\% \text { board/5m) }}\end{array}$ & $\begin{array}{c}\text { \% Ground floor } \\
{[\%]}\end{array}$ & \%asement (\%) \\
\hline Uppeak & 15 & 150 & 50 & 50 \\
\hline Down & 10 & 100 & 50 & 50 \\
\hline Interfloor & 5 & 50 & & \\
\hline
\end{tabular}

Figure 4. Traffic configuration screen 


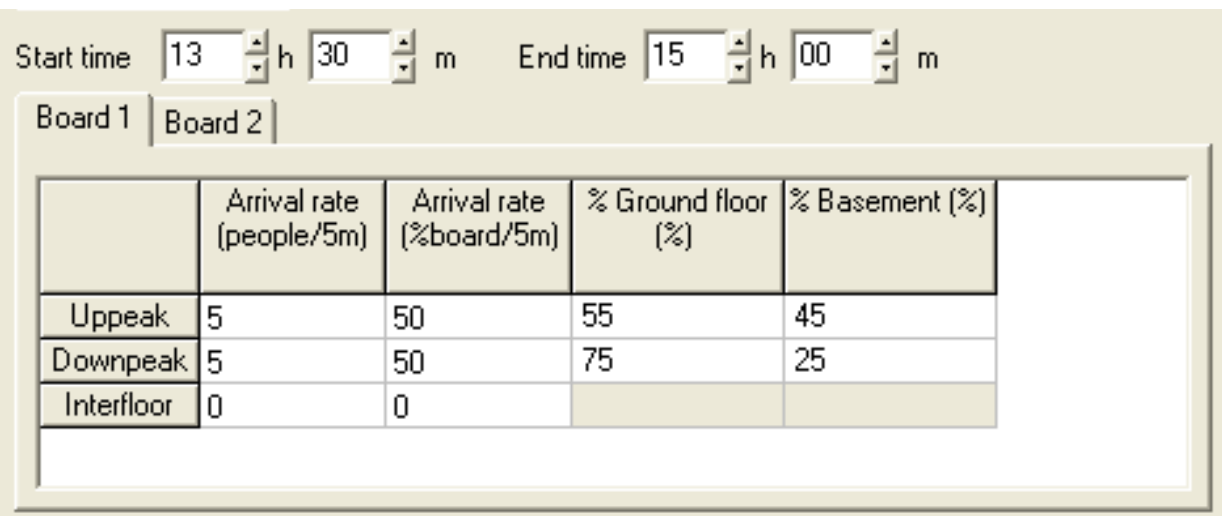

Figure 5. Lunchpeak traffic configuration using constant arrival rate

\begin{tabular}{|c|c|c|c|c|c|c|}
\hline Start time 8 & $\frac { 4 } { h } \longdiv { 0 }$ & ㅎ $\mathrm{m}$ & time 9 & 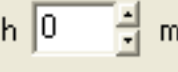 & & \\
\hline Board $1 \mid B$ & $\operatorname{ard} 2 \mid$ & & & & & \\
\hline & $\begin{array}{c}\text { Arrival peak } \\
\text { rate } \\
\text { (people } / 5 \mathrm{~m} \text { ) }\end{array}$ & $\begin{array}{c}\text { Arrival peak } \\
\text { rate } \\
\text { [\%board } / 5 \mathrm{~m} \text { ] }\end{array}$ & $\begin{array}{c}\text { Base arrival } \\
\text { rate (pers } / 5 \mathrm{~m} \text { ) }\end{array}$ & $\begin{array}{c}\text { Base arrival } \\
\text { rate } \\
\text { [\%board } / 5 \mathrm{~m} \text { ) }\end{array}$ & Peak width (m). & $\%[$ \\
\hline Uppeak & 12 & 120 & 5 & 50 & 10 & 55 \\
\hline Down & 0 & 0 & 0 & 0 & 0 & 75 \\
\hline Interfloor & 0 & 0 & 0 & 0 & 0 & \\
\hline$\leq$ IIIII & & & & & & $>$ \\
\hline
\end{tabular}

Figure 6. Uppeak traffic configuration using peak pattern 


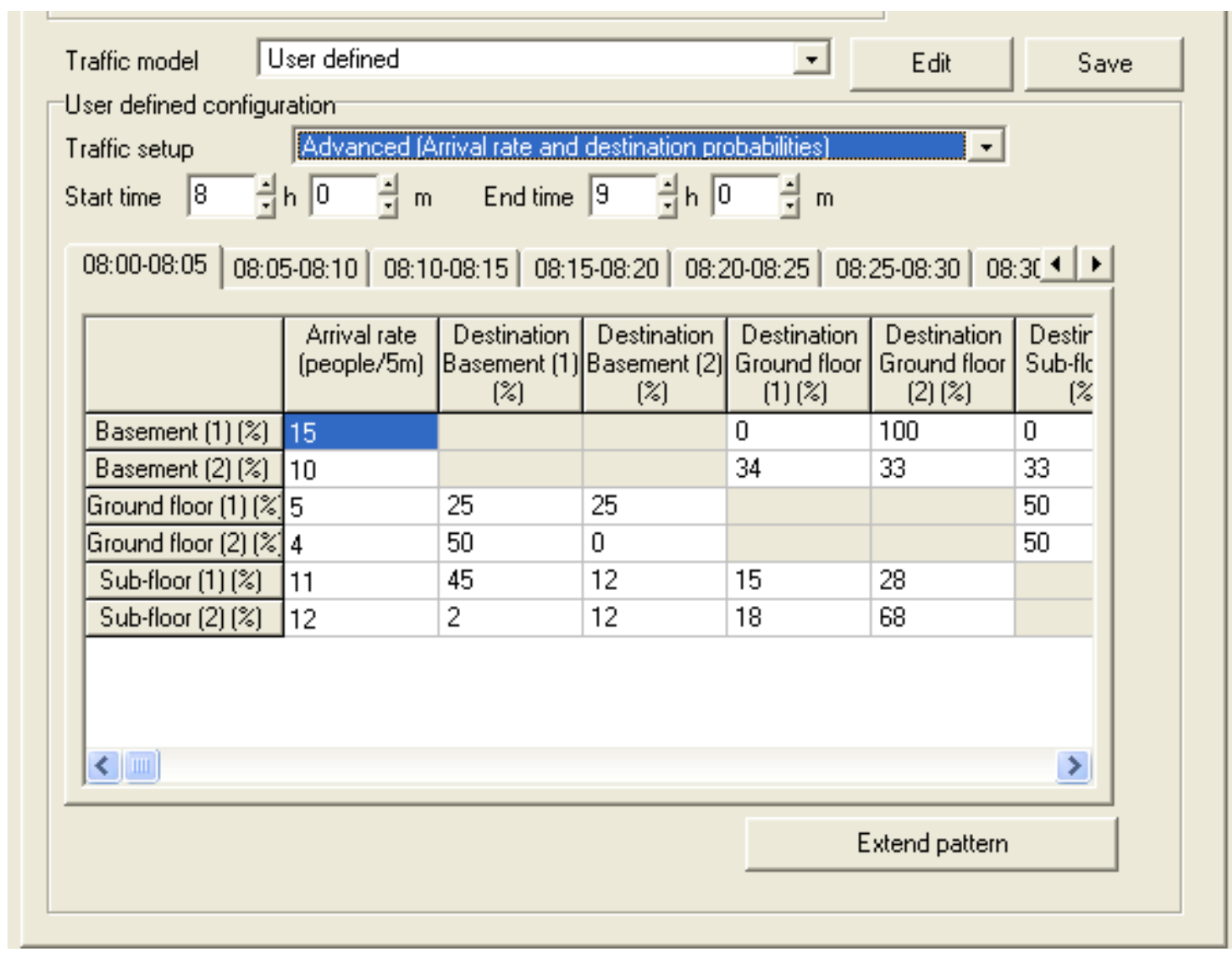

Figure 7. Traffic pattern advanced configuration 
Data input

囲 Building| in Traffic $\square$ Elevators $\mid \sum_{\Omega}^{2}$ Algorithm | 圈 Report $\mid$

No of elevator

\begin{tabular}{|llll|l|l|}
\hline 1 & 4 & 7 & 10
\end{tabular}$\quad$ Closed boards

$\begin{array}{llll}2 & 5 & 8 & 11\end{array}$

$\begin{array}{llll}3 & 6 & 9 & 12\end{array}$

Car parameters

Car models User defined Edit

Save

Capacities [kg]

100,00

200,00

300,00

500,00

1000,00

\section{Edit capacities..}

Door times

Pre-opening

Opening

Closing

Closing wait 1

Closing wait 2

\begin{tabular}{|c|c|}
\hline 0 & $\frac{1}{7}$ \\
\hline 1 & $\frac{\Delta}{*}$ \\
\hline 2 & 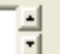 \\
\hline 3,5 & $\frac{1}{*}$ \\
\hline 2 & $\frac{1}{4}$ \\
\hline
\end{tabular}

Kinematics (As, Ad [m/s $]$ ] $\mathrm{Vn}, \mathrm{V} /[\mathrm{m} / \mathrm{s}] ; \mathrm{T} s, \mathrm{TI}[\mathrm{s}])$

3VF $A s=2.50 \mathrm{Ad}=2.50 \mathrm{Vn}=1.00 \mathrm{~V}=0.10 \mathrm{~T} a=0.50 \mathrm{Tl}=1.00$

Kinematics 1

Kinematics 2

Kinematics 3

Kinematics 4

\section{Edit kinematics...}

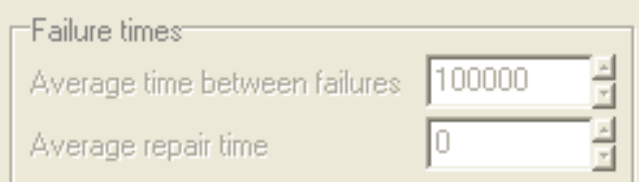

DK 

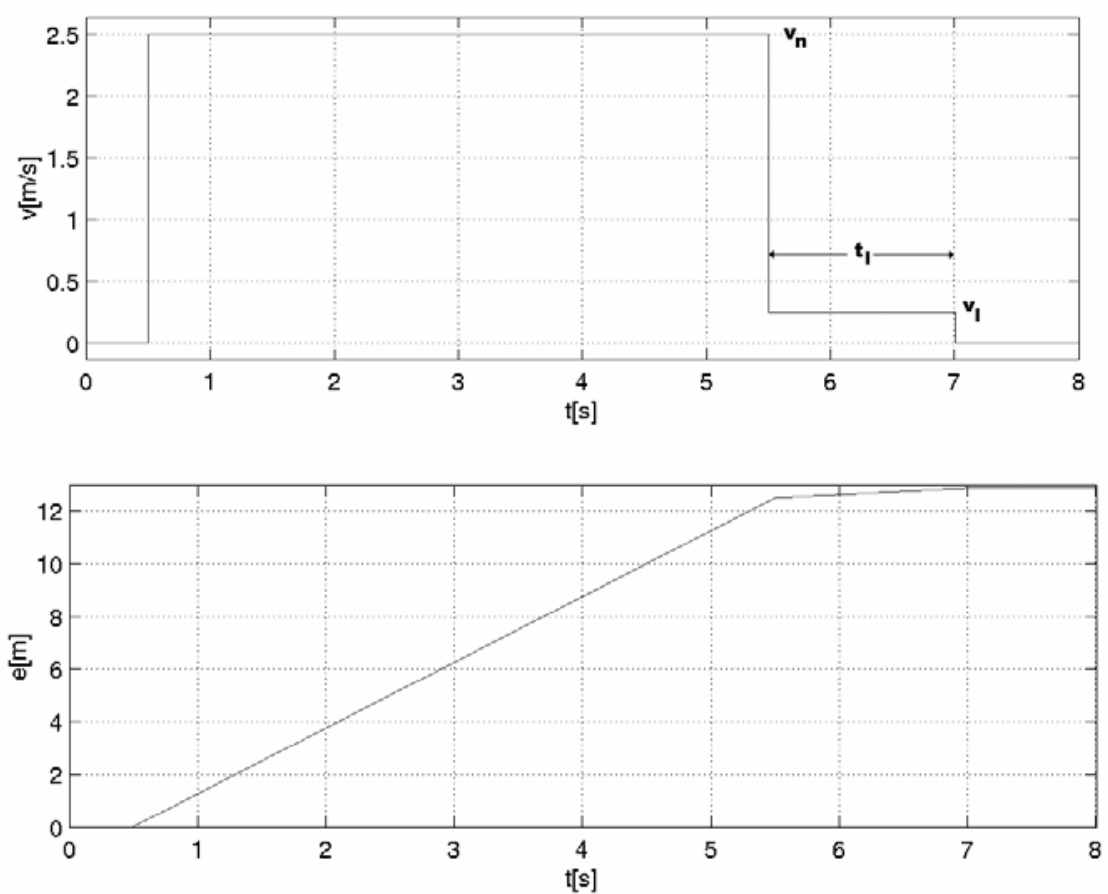

Figure 9. Speed (upper graphic) and distance for 2-speed kinematic
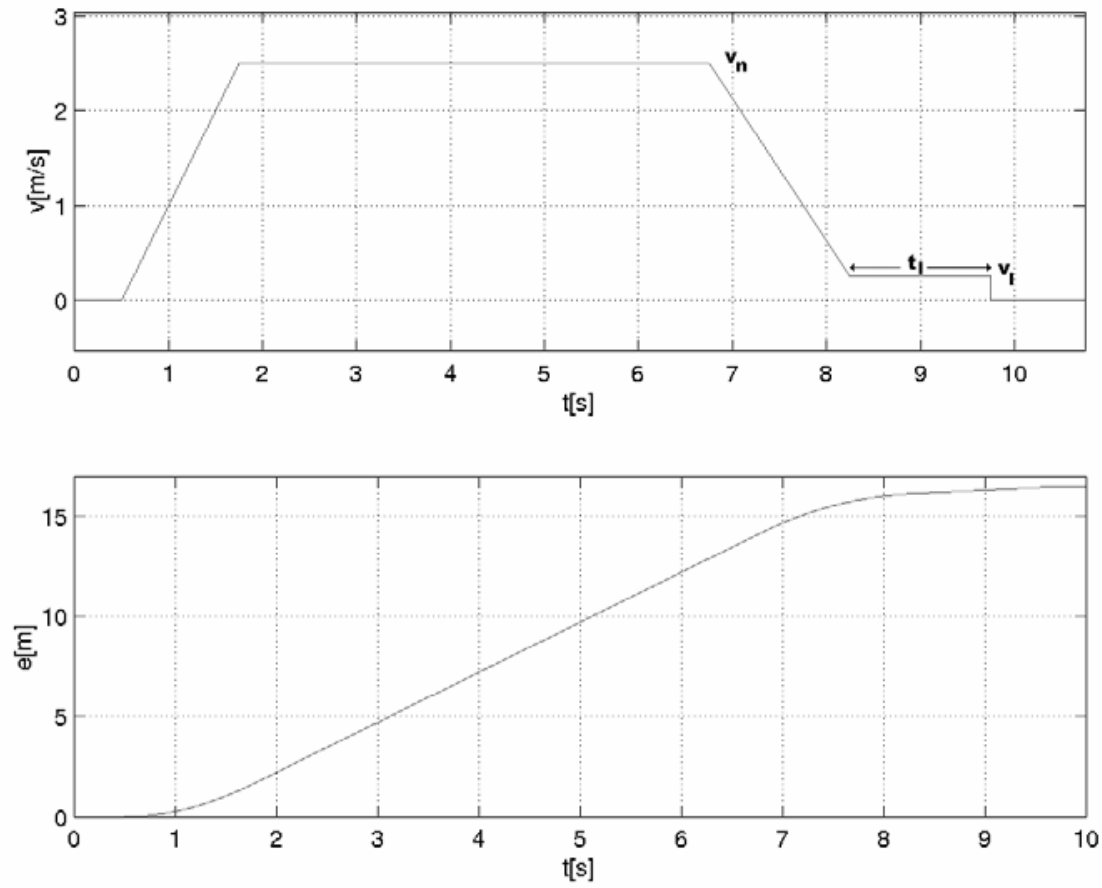

Figure 10. Speed (upper graphic) and distance for 3VF kinematics 


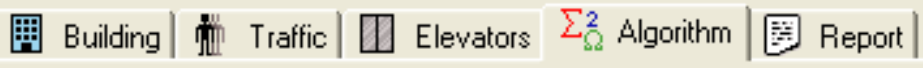

Algorithm MicroBasic …"...

Parameters

Group

- Up/Down

C Down

C Up

Uppeak/Downpeak control

$\sqrt{\checkmark}$ Uppeak Soft fron $\sqrt{0} \div \mathrm{h} \sqrt{0} \div \mathrm{m}$ to $\sqrt{0} \div \mathrm{h} \sqrt{0} \div \mathrm{m}$ Floor Basement

Hard fron $0 \div \mathrm { h } \longdiv { 0 } \div \mathrm { m }$ to $0 \div \mathrm{h} 0$ 의 $\mathrm{m}$

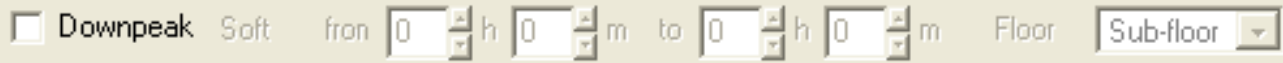

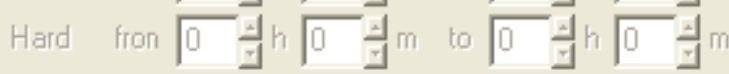

Maximum waiting time $\longdiv { 3 0 9 }$ if $s$

Figure 11. Control and optimization algorithm configuration screen 


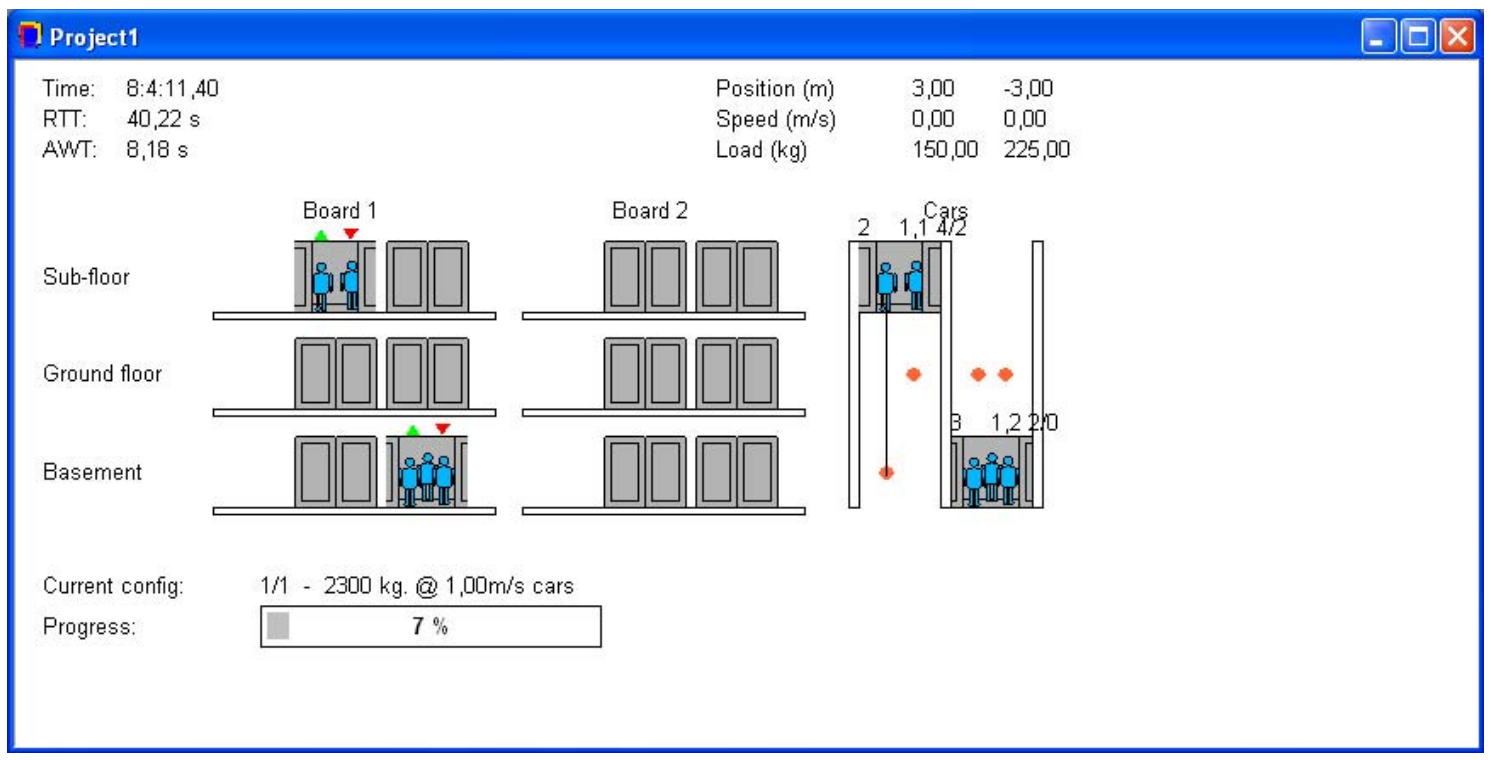

Figure 12. Animation zone: simulation screen 
Data input

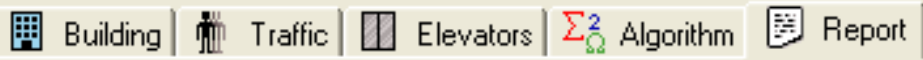

Global results

『 Waiting time

$\sqrt{\checkmark}$ Trip time

$\sqrt{\checkmark}$ System time

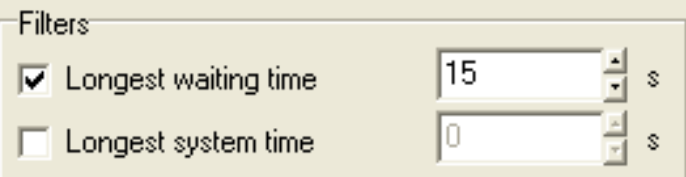

Order by

AWT $\quad \longrightarrow$

Elevators

$\sqrt{\checkmark}$ Position

$\Gamma$ Load

Description

Project description

Floors

$\lceil$ Queue size

$v$ Arrival rate

$\Gamma$ Waiting time

Figure 13. Report configuration screen 


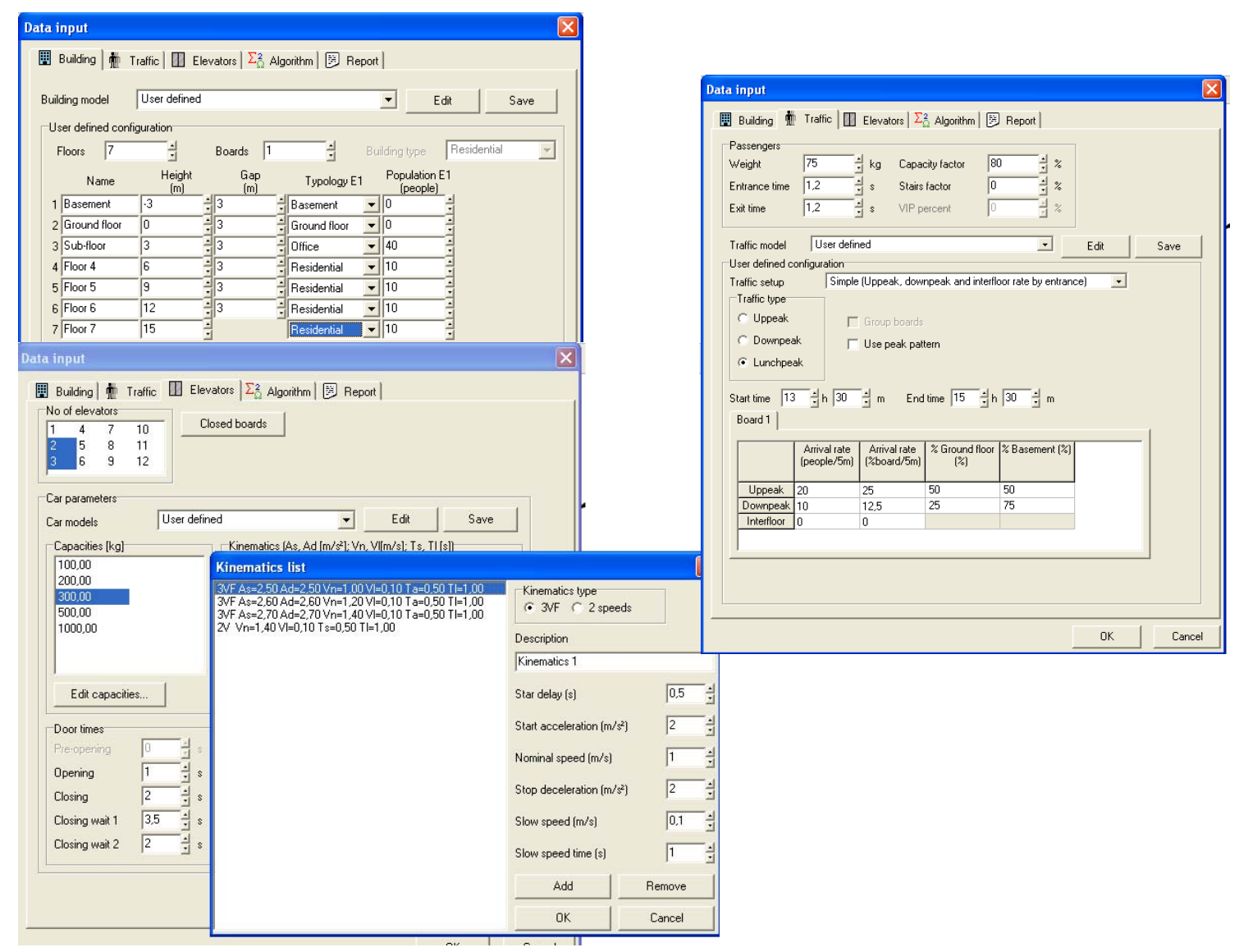

Figure 14. Input data for the case study 


\section{CONFIGURATION 1}

$\begin{array}{ll}\text { Elevators } & \\ \text { No of elevators: } & 2 \\ \text { Capacty: } & 300,00 \mathrm{~kg} \\ \text { Nonemades: } & 3 \mathrm{VF} \\ \quad \text { Start delay: } & 0,50 \mathrm{~s} \\ \text { Start acceleration: } & 2,50 \mathrm{~m} / \mathrm{s}^{2} \\ \text { Nominal spesd: } & 1,00 \mathrm{~m} / \mathrm{s} \\ \text { Stop deceleration: } & 2,50 \mathrm{~m} / \mathrm{s}^{2} \\ \text { Slow spesd: } & 0,10 \mathrm{~m} / \mathrm{s} \\ \text { Slow speed time: } & 1,00 \mathrm{~s}\end{array}$

Global results

Round trip the (RTT)

50,38 s

Average wating time (AwT): Longest waiting time (LWT):

28,55 s

$10 \%$ of possengers watred less than 0,00 ?

s0\% of passengers wathed less than 17,91 s

$90 \%$ of pocsengers wathed for less than 66,67 =

Average fourney time (AT): Longest fourney time (LT):

$26,67=$ 286,40 s

$10 \%$ of pacsengers wathed for less than 12,9.1 : so\% of passengers wathed less than $20,90=$ $90 \%$ of posengers wathed less than $39,80 \mathrm{~s}$
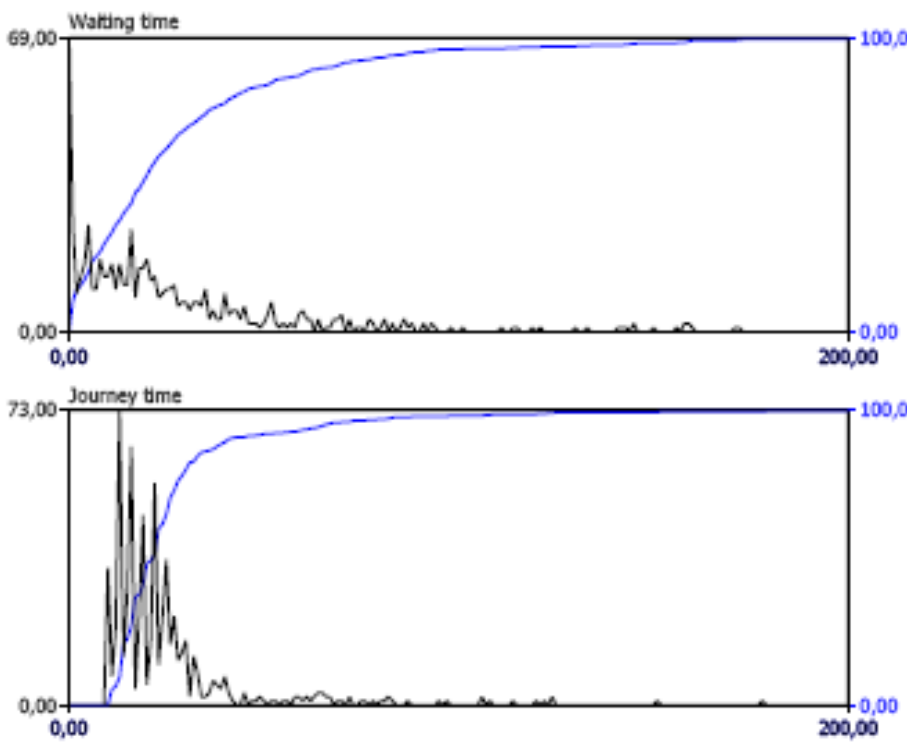

Average tobl time (ATT):

$55,30 \leq$

Longest total time (LTT):

287,40 s

$10 \%$ of possengers spent less than 13,91 =

sock of posengers went less than 42,79 s

$90 \%$ of pacsengers spent less than 102,49 s

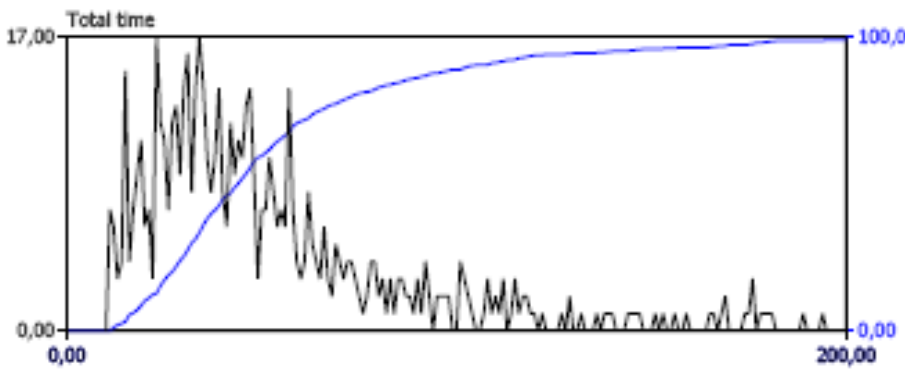

Algorithm results

$\begin{array}{ll}\text { Average processing time: } & 0,00 \mu \mathrm{s} \\ \text { Maximum processing time: } & 0,00 \mu \mathrm{s}\end{array}$

Figure 15. AWT, AJT and ATT graphical results 


\section{Elevators results}

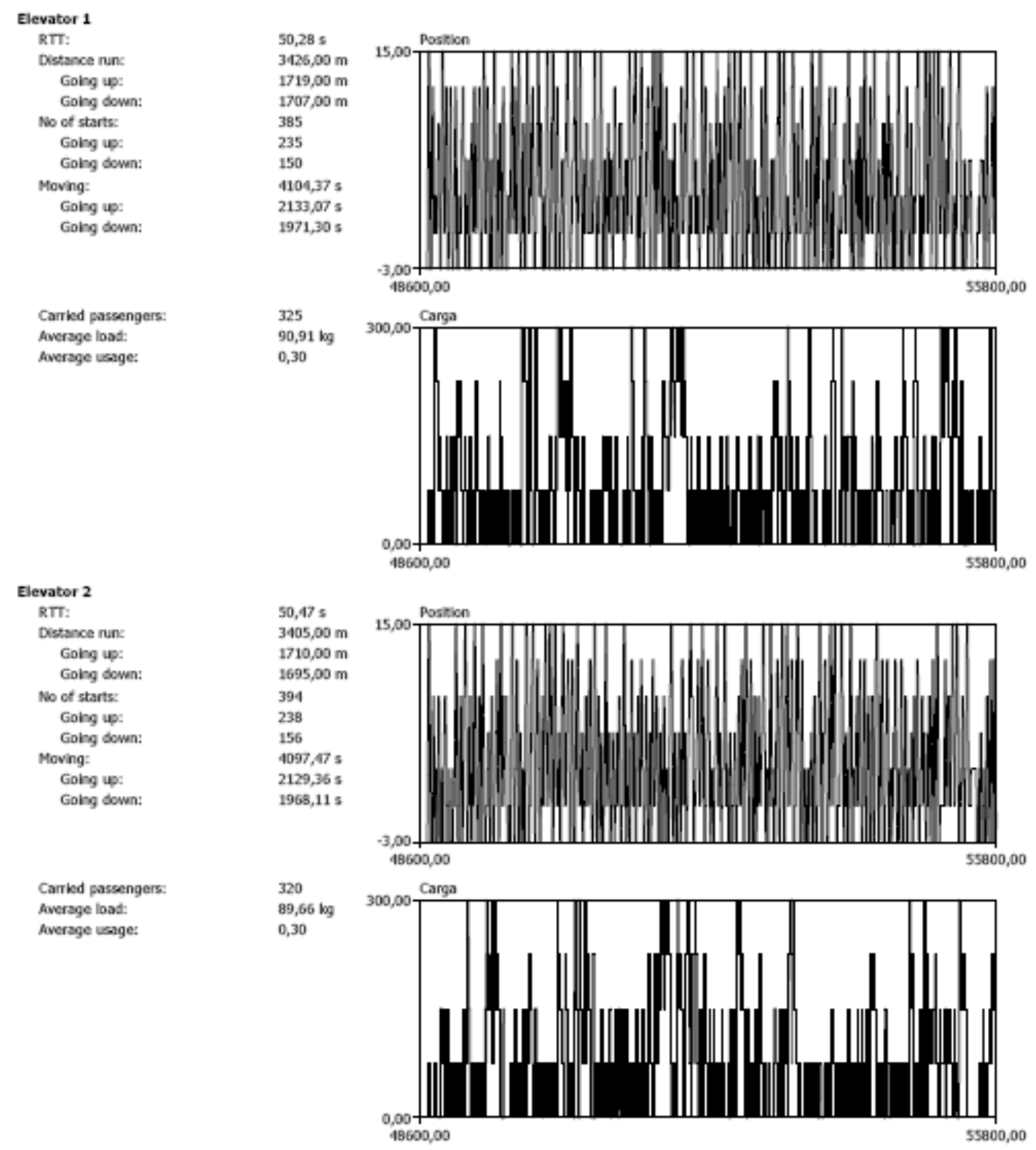

Figure 16. Elevator graphical results 
Floor results

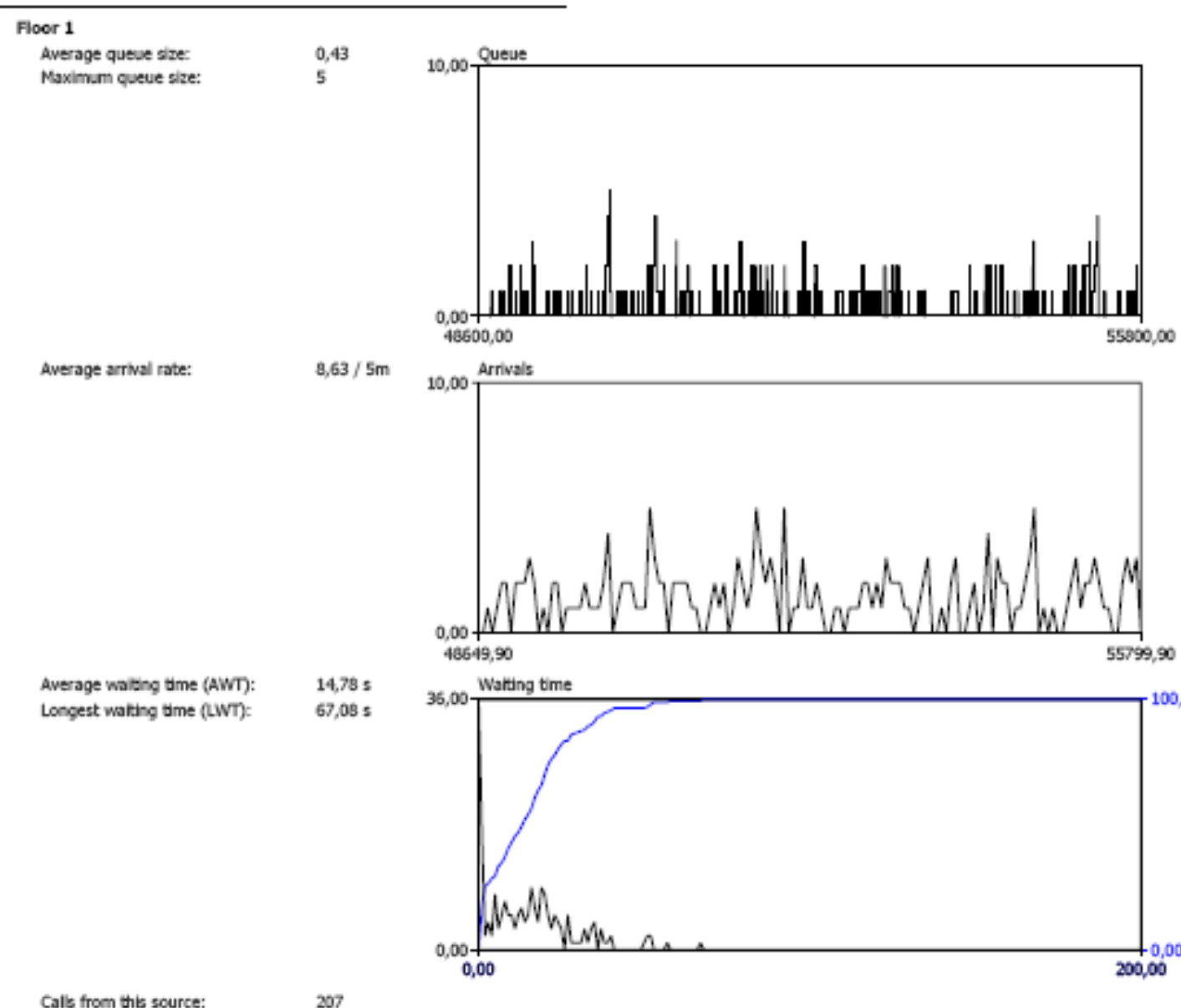

from this source:

180

Figure 17. Graphical results for ground floor 